\title{
Exigências de proteína de bovinos anelorados em pastejo
}

\author{
Eduardo Henrique Bevitori Kling de Moraes ${ }^{2}$, Mário Fonseca Paulino ${ }^{3}$, Kamila Andreatta \\ Kling de Moraes ${ }^{4}$, Sebastião de Campos Valadares Filho ${ }^{3}$, Darcilene Maria de Figueiredo ${ }^{5}$, \\ Victor Rezende Moreira Couto ${ }^{6}$
}

\author{
${ }^{1}$ Pesquisa parcialmente financiada pelo CNPq e pela FAPEMIG \\ 2 Departamento de Zootecnia/ICAA/UFMT, Sinop-MT, CEP: 78550-000. Pesquisador do INCT-CA. \\ ${ }^{3}$ Departamento de Zootecnia/UFV, Viçosa-MG, CEP: 36570-000. Bolsista do CNPq. \\ ${ }^{4}$ Departamento de Zootecnia/ICAA/UFMT, Sinop-MT, CEP: 78550-000. \\ ${ }^{5}$ Departamento de Zootecnia/UFAL, Arapiraca, AL, CEP: 57309-005. \\ ${ }^{6}$ Doutorando, Bolsista do CNPq, DZO-UFV, Viçosa, MG, CEP: 36570-000.
}

RESUMO - Objetivou-se determinar as exigências proteicas de bovinos anelorados sob pastejo em cinco piquetes de Brachiaria decumbens. Utilizaram-se 27 animais não-castrados, com peso corporal (PC) médio inicial de 311,0 kg e idade média de 14 meses. Três animais foram abatidos após o período de adaptação para servirem como referência para as estimativas do peso de corpo vazio (PCVZ) e da composição corporal iniciais dos animais mantidos no experimento. Dos 24 animais restantes, quatro foram designados ao grupo mantença, que teve tempo de pastejo restrito. Os 20 demais foram distribuídos em quatro tratamentos: mistura mineral, autocontrole e duas frequências de alimentação: três vezes/semana (às segunda, quartas e sextas-feiras) ou diariamente. As exigências líquidas de proteína para ganho diminuíram com o aumento do peso vivo (PV) dos animais. A exigência líquida de proteína encontrada para um animal com peso corporal de $250 \mathrm{~kg}$ foi de 153,71 g/kg GPCVZ, enquanto para um animal de $400 \mathrm{~kg}$ foi de 141,86 g/kg GPCVZ. A seguinte equação foi obtida para estimativa da proteína retida em relação ao ganho de peso vivo em jejum (GPVJ) e da energia retida (ER): PR (g/dia) = -34,6109 + 257,956*GPVJ 17,01*ER. As exigências de proteína metabolizável estimadas para mantença e ganho de peso foram de 357,77 e 288,33 g/kg PC, respectivamente, para um bovino não-castrado de $400 \mathrm{~kg}$ de PC sob pastejo. Animais que consomem suplementos proteicos apresentam maiores exigências de proteína degradável no rúmen (PDR) em comparação a animais sem suplementação, em virtude do maior consumo de nutrientes digestíveis totais. Para um animal de $400 \mathrm{~kg}$ de PV sob suplementação, as exigências de proteína degradável no rúmen e proteína não-degradável no rúmen são de 764,22 e 73,89, respectivamente, que correspondem à exigência de proteína bruta de 838,10 g/dia.

Palavras-chave: pasto, proteína bruta, requerimento, zebuínos

\section{Protein requirements of grazing Zebu steers}

ABSTRACT - The objective of this study was to determine the protein requirements of Zebu sterrs grazing grazing five Bracharia decumbens paddocks. Twenty-seven steers averaging initial body weight (BW) of $311.0 \mathrm{~kg}$ and 14 months old were used. Three animals were slaughtered after the adaptation peiod to serve as reference for the estimate of empty body weight (EBW), and the initial body composition of the animals kept in the experiment. Among the 24 remaining animals, four were placed in the maintenance group, with restricted grazing time. The other 20 were allotted to four treatments: mineral mixture, self-feed and two feeding frequencies (three times a week, Monday, Wednesday and Friday, or daily. The net protein requirements for gain decreased as body weight increased. The protein requirement detected for an animal with $250 \mathrm{~kg}$ BW was $153.71 \mathrm{~g} / \mathrm{kg}$ EBW, while for an animal of $400 \mathrm{~kg}$ live weight it was $141.86 \mathrm{~g} / \mathrm{kg}$ EBG. The following equation was obtained to estimate the retained protein (RP) in function of the fasting live weight gain (LWG) and the retained energy (RE): $\mathrm{RP}=-34.6109+257.956 * \mathrm{LWG}-17.01 * \mathrm{RE}$. The metabolizable protein requirements estimated for maintenance and gain were 357.77 and $288.33 \mathrm{~g} / \mathrm{kg} \mathrm{BW}$, respectively, for a $400 \mathrm{~kg}$ BW grazing steer. The animals fed protein supplementation presented greater degradable protein requirements in the rumen than non-supplemented animals, due the greater intake of total digestible nutrients (TDN). For an animal with $400 \mathrm{~kg}$ BW fed protein supplementation, the daily requirements for degradable protein in the rumen and non-degradable protein are, respectively, 764.22 and $73.89 \mathrm{~g}$ that corresponded to a crude protein requirement of $838.10 \mathrm{~g} /$ day.

Key Words: crude protein, pasture, requirements, zebu cattle

Recebido em 16/5/2008 e aprovado em 17/3/2009.

Correspondências devem ser enviadas para: edukling@ufmt.br 


\section{Introdução}

O manejo nutricional é um dos principais fatores que afetam a produção de ruminantes, pois a alimentação determina a maior parcela dos custos da atividade. Assim, o pecuarista deve procurar aumentar a utilização do pasto, que é o alimento mais barato da dieta de bovinos e essencial para aumento da rentabilidade no sistema produtivo.

Segundo Boin (1995), o balanceamento de rações e suplementos concentrados para determinados níveis de desempenho, assim como a estimativa do desempenho a partir de dietas balanceadas, requer o conhecimento das exigências nutricionais para diversas funções e níveis de desempenho. O bovino em pastejo se insere em um ciclo que se altera dinamicamente de acordo o ambiente e com mudanças nos requerimentos e no suprimento de forragem (Noller et al., 1996). Desta forma, para que os animais possam expressar seu potencial genético para a produção de carne, devem ser atendidas suas exigências nutricionais.

Apesar de as pastagens serem a base da pecuária nacional, são poucas as informações sobre exigências de proteína de bovinos de corte em pastejo e, delas, a maioria é obtida com animais em regime de confinamento.

Segundo o NRC (2000), o grande número de raças de bovinos, a diversidade de cruzamentos, a utilização de agentes anabolizantes, a condição sexual dos animais e os sistemas de alimentação e de classificação de carcaça adotados na América do Norte tornam os sistemas Europeu (ARC) e Australiano (CSIRO), utilizados para estimar as exigências de proteína, impróprios às condições norteamericanas. Com base nesta afirmativa, pode-se inferir que esses sistemas não são apropriados também para as condições tropicais, o que justifica o desenvolvimento de pesquisas sobre as exigências nutricionais, a fim de se obter maior número de informações para aperfeiçoamento da tabela de exigências nutricionais de animais em condições tropicais.

Assim, objetivou-se com este trabalho estimar as exigências de proteína para ganho de peso em bovinos anelorados criados no sistema pasto-suplemento no período das águas e na transição águas/seca.

\section{Material e Métodos}

O experimento foi conduzido entre os meses de março e junho de 2003, utilizando-se 27 bovinos anelorados, nãocastrados, com 14 meses de idade e peso médio inicial de $311,0 \mathrm{~kg}$. No início do período experimental, foram abatidos três animais que serviram de referência no estudo da composição corporal inicial. Os 24 animais restantes foram distribuídos em delineamento inteiramente casualizado entre os tratamentos: mantença; mistura mineral; autocontrole; e duas frequências de oferta de suplementos proteicos três vezes/semana (segunda, quarta e sexta) e diariamente (Tabela 1), com 5 repetições por tratamento, exceto o mantença, que teve 4 repetições. O grupo autocontrole foi formulado com $10 \%$ de ureia/sulfato de amônia e $10 \%$ de mistura mineral com o objetivo de que o próprio animal controlasse o consumo do suplemento.

A quantidade de suplemento fornecida foi de $1,283 \mathrm{~kg}$ aos animais sob suplementação três vezes por semana e 0,550 kg ao grupo sob suplementação diária. Ao final de sete dias, cada animal recebeu a mesma quantidade de suplemento (3,850 kg/animal/semana).

Foram destinados ao grupo mantença quatro animais, escolhidos ao acaso, submetidos a pastejo restrito objetivando atender às exigências de mantença. Os animais foram soltos no piquete às $6 \mathrm{~h}$ da manhã e presos em um curral às $10 \mathrm{~h}$, perfazendo quatro horas de pastejo diário para se manter a ingestão de alimento em nível pouco acima da exigência de mantença (Fontes et al., 2005). O período experimental foi de 84 dias e os animais foram pesados ao início do experimento e posteriormente a cada 28 dias.

A área experimental foi constituída de cinco piquetes de Brachiaria decumbens Stapf. (2,0 ha cada), providos de bebedouros e comedouros cobertos. Com o objetivo de reduzir a influência da possível variação na disponibilidade de MS de pasto, os animais foram mantidos em cada piquete por sete dias e, após este período, procedeu-se ao rodízio entre os piquetes mantendo-se a aplicação dos mesmos tratamentos aos animais.

A amostragem da forragem ingerida pelos animais foi realizada por simulação manual de pastejo a cada 15 dias. O ensaio de digestibilidade foi realizado no início da segunda pesagem dos animais após 46 dias experimentais e teve duração de 12 dias. A excreção fecal foi estimada utilizando-se óxido crômico, aplicado em dose única diária, calculada com base na razão entre a quantidade do indicador fornecido e sua concentração nas fezes:

Tabela 1 - Composição percentual dos suplementos, com base na matéria natural

\begin{tabular}{lccc}
\hline Ingrediente & \multicolumn{3}{c}{ Suplemento } \\
\cline { 2 - 4 } & Mistura mineral & Autocontrole & Frequência \\
\hline Mistura mineral & 100 & 10 & 10 \\
Ureia/sulfato de & - & 10 & - \\
amônia (9:1) & - & - & 50 \\
Farelo de soja & - & - & 40 \\
Farelo de glúten de & - & 80 & - \\
milho (21\% PB) & - & & \\
Farelo de trigo & & &
\end{tabular}

R. Bras. Zootec., v.39, n.3, p.601-607, 2010 
ExcreçãoFecal $(\mathrm{kg} /$ dia $)=\frac{\text { Quantidadefornecida do indicador }(\mathrm{g})}{\text { Concentração do indicadornas fezes }(\mathrm{g} / \mathrm{kgMS})} \times 100$

O indicador foi aplicado em dose única diária (15 g/ animal) acondicionado em cartuchos de papel e introduzido, por meio de um aplicador, diretamente no esôfago dos animais durante nove dias consecutivos. Após seis dias de aplicação, foram coletadas fezes dos animais no sétimo (às 8 h), oitavo (às 12 h) e nono (às 16 h) dias. As estimativas do consumo voluntário foram obtidas empregando-se como indicador interno a fibra em detergente neutro indigestível (FDAi), utilizando-se a seguinte equação:

$$
C M S=\frac{[(E F \times C I F)-I S]}{C I F O}+C M S S
$$

em que: $\mathrm{EF}$ = excreção fecal (kg/dia); $\mathrm{CIF}$ = concentração do indicador nas fezes $(\mathrm{kg} / \mathrm{kg})$; IS = indicador presente no suplemento (kg/dia); CIFO = concentração do indicador na forragem $(\mathrm{kg} / \mathrm{kg})$; e CMSS = consumo de matéria seca de suplemento (kg/dia).

As amostras de pasto e fezes foram pré-secas em estufa de ventilação forçada a aproximadamente $60^{\circ} \mathrm{C}$ por 72 horas e posteriormente moídas em moinho de faca com peneira de malha de $1 \mathrm{~mm}$. As análises laboratoriais das amostras de pasto e fezes foram realizadas de acordo com técnicas descritas por Silva \& Queiroz (2002) para determinação da composição química dos suplementos e do pasto (Tabela 2).

O abate dos animais foi realizado por concussão cerebral, seguida de seç̧ão da veia jugular, após um período de 16 horas de jejum de sólidos, de forma escalonada, de modo que os animais sob suplementação 3 vezes por semana, diariamente e aqueles dos grupos autocontrole e mistura mineral foram abatidos, respectivamente, após 98, 103, 105 e 110 dias de suplementação. A cada abate foi sorteado um animal do grupo mantença para ser abatido juntamente com os demais. Os pesos de abate foram de 252,5; 390,0; 402,0; 404,0 e 406, respectivamente, para mantença, mistura mineral, autocontrole e com suplementação 3 vezes por semana ou diariamente.
Durante o abate, foram pesadas e coletadas de cada animal amostras de sangue, vísceras, órgãos, couro, cauda, cabeça e membros. As vísceras e os órgãos foram lavados e seus pesos somados aos das demais partes do corpo (carcaça, couro, cabeça, membros e sangue total) para determinação do peso corporal vazio (PCVZ) de cada animal.

As amostras de sangue foram coletadas imediatamente após a secção da veia jugular dos animais, acondicionadas em recipiente de vidro e deixadas em estufa de ventilação forçada a aproximadamente $60^{\circ} \mathrm{C}$ durante 72 horas.

A carcaça dos animais foi seccionada longitudinalmente em meias-carcaças, que foram pesadas e resfriadas em câmara fria a $-5^{\circ} \mathrm{C}$ durante aproximadamente 20 horas. Decorrido esse tempo, a meia-carcaça direita foi retirada da câmara fria e totalmente dissecada para separação dos tecidos muscular, adiposo e ósseo, que foram posteriormente pesados.

Após a moagem dos órgãos, das vísceras, da gordura e do músculo, e a seç̧ão dos ossos (carcaça, cabeça e membros), da cauda e do couro, as amostras foram acondicionadas em vidro $(500 \mathrm{~mL})$ e levadas à estufa a $105^{\circ} \mathrm{C}$ por 72 a 96 horas para determinação da MS gordurosa. Em seguida, cada amostra foi lavada com éter de petróleo para obtenção da matéria seca predesengordurada (MSPD). As amostras foram trituradas em moinho de bola para posteriores determinações de nitrogênio total (NT) e extrato etéreo, conforme descrito por Silva \& Queiroz (2002), e do teor de $\mathrm{PB}$, obtido pelo produto entre o nitrogênio total e o fator 5,88, conforme descrito por Baldwin (1995). A gordura removida no pré-desengorduramento foi calculada pela diferença entre a matéria seca gordurosa e a matéria seca pré-desengordurada, cujo resultado foi adicionado aos de extrato etéreo residual na matéria seca e predesengordurada, para determinação do teor total de gordura. A partir dos teores de proteína e extrato etéreo na matéria seca predesengordurada e do peso da amostra submetida ao predesengorduramento, foram determinados os respectivos teores na matéria natural.

Tabela 2 - Composição química dos suplementos e do pasto

\begin{tabular}{|c|c|c|c|c|}
\hline \multirow[t]{2}{*}{ Item } & \multicolumn{3}{|c|}{ Suplemento } & \multirow[t]{2}{*}{ B. decumbens } \\
\hline & Mistura mineral & Autocontrole & Frequência & \\
\hline Matéria seca (\%) & 98,75 & 89,57 & 89,97 & 24,73 \\
\hline Matéria orgânica (\% MS) & - & 74,10 & 83,78 & 89,95 \\
\hline Proteína bruta (\% MS) & - & 39,84 & 33,66 & 8,91 \\
\hline Extrato etéreo (\% MS) & - & 2,42 & 1,79 & 1,21 \\
\hline Carboidratos totais (\% MS) & - & 31,84 & 48,33 & 79,83 \\
\hline Fibra em detergente neutro (\% MS) & - & 34,62 & 23,50 & 75,12 \\
\hline Carboidratos não-fibrosos (\% MS) & - & 13,32 & 22,81 & 4,71 \\
\hline Fibra em detergente ácido (\% MS) & - & 11,50 & 11,24 & 44,15 \\
\hline Lignina (\% MS) & - & 2,69 & 1,62 & 4,48 \\
\hline
\end{tabular}


A relação entre o peso de corpo vazio e o peso vivo dos animais-referência foi utilizada para estimativa do peso de corpo vazio inicial dos animais que permaneceram em alimentação. Foram sorteados dois animais representantes de cada grupo para retirada de amostras da cabeça e de um membro anterior e outro posterior para separação física de músculos, gordura, ossos e couro.

Os conteúdos corporais de proteína no peso de corpo vazio foram determinados de acordo com suas concentrações percentuais nos órgãos, nas vísceras, no couro, no sangue, na cauda, na cabeça, nos membros e nos constituintes separados (gordura, músculos e ossos) da carcaça.

Os conteúdos de proteína retida no corpo dos animais de cada grupo e de todos os grupos em conjunto foram estimados por meio de equações de regressão do logaritmo do conteúdo corporal de proteína em função do logaritmo do PCVZ, segundo o ARC (1980). Equações foram construídas adicionando-se os valores relativos aos animais-referência para os animais sob suplementação e sem suplementação.

Derivando-se as equações de predição do conteúdo corporal de proteína em função do logaritmo do PCVZ, foram obtidas as exigências líquidas de proteína por kg de ganho de PCVZ (GPCVZ) a partir de equação: $Y^{\prime}=b \cdot 10^{a} \cdot X^{b-1}$; em que: Y'= exigências líquidas de proteína; $a$ e b = intercepto e coeficiente de regressão, respectivamente, das equações das exigências líquidas de proteína; $X=$ PCVZ (kg).

Para a conversão do peso vivo em PCVZ, dentro do intervalo de pesos incluído neste estudo, calculou-se a relação entre o PCVZ e o peso vivo dos animais sob suplementação. Para conversão das exigências para ganho de PCVZ em exigências para ganho de peso vivo, utilizou-se o fator obtido a partir dos dados experimentais.

Os resultados foram interpretados estatisticamente por meio de análises de variância e as comparações entre as equações de regressão dos parâmetros avaliados para cada tratamento foram realizadas de acordo com a metodologia recomendada por Regazzi (1996) para testar identidade de modelos.

\section{Resultados e Discussão}

A relação obtida para estimativa do peso de corpo vazio (PCVZ) a partir do peso vivo dos animais deste estudo foi: $\mathrm{PCVZ}=\mathrm{PV} * 0,8877$. Esse valor é próximo ao recomendado pelo NRC (2000), de 0,8910, e do valor de 0,8975 observado por Silva et al. (2002a) em animais Nelore em confinamento. Por outro lado, com animais Nelore a pasto, Fregadolli (2005) observaram relação de 0,8746 entre PCVZ e PV.

Adotou-se o fator 0,9013, obtido a partir dos dados experimentais, para conversão das exigências para ganho de PCVZ (GPCVZ) em exigências para ganho de peso vivo (GPV), ou seja, deve-se multiplicar as exigências em relação ao ganho de peso de corpo vazio por 0,9013 para encontrar as exigências de acordo com o ganho de peso vivo. Paulino et al. (2004) encontraram relação entre GPCVZ e GPV de 0,900, próxima deste estudo. O NRC (2000) utiliza a relação 0,956 entre o GPCVZ e o GPV.

Adotou-se uma única equação para a estimativa do conteúdo corporal de proteína (Tabela 3), visto que o teste de identidade entre os modelos, aplicado às equações de regressão do logaritmo do conteúdo corporal de proteína (kg), em função do logaritmo do PCVZ (kg), indicou não haver diferença entre os tratamentos.

Nas estimativas do conteúdo corporal de proteína total no peso vivo e no peso de corpo vazio (Tabela 4), o conteúdo corporal de proteína aumentou de $45,52 \mathrm{~kg}$ (250 kg PV) para 67,06 kg (400 kg PV) à medida que o PV dos animais aumentou, como consequência do aumento da massa corpórea do animal. Para animais Nelore na faixa de peso vivo de $400 \mathrm{~kg}$ sob pastejo, Fregadolli (2005) estimaram $61,0 \mathrm{~kg}$ de proteína corporal.

A concentração de proteína, quando expressa em $\mathrm{g} / \mathrm{kg}$ PCVZ, diminuiu com o aumento do PV. Quando o PCVZ passou de 221,93 kg (250 kg PV) para 355,08 kg (400 kg PV), a participação do conteúdo de proteína reduziu em torno de 8,61\%. De forma similar, Fregadolli (2005) também observou redução do conteúdo de proteína à medida que o PCVZ do animal aumentou.

Tabela 3 - Parâmetros das equações de regressão do logaritmo do conteúdo de proteína no corpo vazio em função do logaritmo do PCVZ de bovinos anelorados em pastejo

\begin{tabular}{lccc}
\hline Item & \multicolumn{2}{c}{ Parâmetro } & $\mathrm{R}^{2}$ \\
\cline { 2 - 3 } & Intercepto (a) & Coeficiente (b) \\
\hline Sem suplementação & $-0,2471$ & 0,7904 & 0,99 \\
Com suplementação & $-0,3593$ & 0,8428 & 0,97 \\
Conjunta & $-0,3332$ & 0,8305 & 0,95 \\
\hline
\end{tabular}

Tabela 4 - Conteúdo corporal estimado de proteína em função do peso vivo e do peso de corpo vazio de bovinos anelorados em pastejo

\begin{tabular}{ccc}
\hline Peso vivo $(\mathrm{kg})$ & \multicolumn{2}{c}{ Proteína } \\
\cline { 2 - 3 } & $\mathrm{kg}$ & $\mathrm{g} / \mathrm{kg}$ PCVZ \\
\hline 250 & 45,52 & 185,83 \\
300 & 52,83 & 179,72 \\
350 & 60,03 & 175,05 \\
400 & 67,06 & 171,10 \\
\hline
\end{tabular}

$\mathrm{PCVZ}=\mathrm{PV} * 0,8877$ 
De acordo com Berg \& Butterfield (1979), a redução da proteína com o aumento do PCVZ reflete a desaceleração do crescimento do tecido muscular em detrimento ao mais rápido desenvolvimento do tecido adiposo, cuja taxa de crescimento é maior em idades mais avançadas.

As exigências de proteína, por kg de ganho de PCVZ, decresceram à medida que o PV dos animais aumentou (Tabela 5). Esse resultado concorda com as observações de Fregadolli (2005) em animais em pastejo e as de Silva et al. (2002a) e Freitas et al. (2006) em animais em confinamento. Os dados de composição do ganho de peso para bovinos preconizados pelo ARC (1980) evidenciam diminuição na quantidade de proteína depositada por kg de ganho à medida que o animal se torna mais pesado. De fato, Backes et al. (2005) observaram que, tanto zebuínos quanto seus mestiços apresentaram exigências de proteína numericamente maiores na fase de recria em relação à de terminação, o que confirma o fato de que, à medida que se eleva o peso corporal, as exigências de proteína decrescem, como resultado da queda no desenvolvimento muscular.

As exigências líquidas de proteína encontradas para um animal de 400 kg (141,86 g/kg GPCVZ) são muito próximas do valor descrito por Fregadolli (2005), também em pesquisa com animais não-castrados sob pastejo. Em comparação às exigências observadas em animais em confinamento, o valor deste estudo foi $22,4 \%$ e $21,3 \%$ inferior ao das exigências estimadas por Silva et al. (2002a) e Valadares Filho et al. (2006b), respectivamente, para um bovino não-castrado com o mesmo peso vivo. Por outro lado, Véras et al. (2001) e Freitas et al. (2006) encontraram valores próximos aos deste estudo. Por meio da compilação de dados de exigências nutricionais de bovinos de corte no Brasil, Silva et al. (2002b) e Valadares Filho et al. (2006b) estimaram as exigências líquidas de proteína para ganho de peso de bovinos Zebu não-castrados em 151,51 g/kg GPCVZ e 172,08 g/kg GPCVZ, respectivamente. Conforme reportado por Paulino et al. (2005), em todos esses trabalhos, a composição corporal não foi mensurada diretamente, mas sim estimada pelo corte da 9-10-11 $\underline{\text { a }}$ costelas, o que pode ocasionar divergências na estimação das exigências.

Tabela 5 - Exigências líquidas de proteína de bovinos anelorados em pastejo

\begin{tabular}{cc}
\hline Peso vivo $(\mathrm{kg})$ & Exigência de proteína $(\mathrm{g} / \mathrm{kg}$ GPCVZ) \\
\hline 250 & 154,33 \\
300 & 149,64 \\
350 & 145,78 \\
400 & 142,51 \\
\hline
\end{tabular}

$\mathrm{PCVZ}=\mathrm{PV}^{*} 0,8877$.
Foi desenvolvida uma equação de regressão da proteína retida $(P R)$, em função da energia retida (ER, $\mathrm{Mcal} / \mathrm{dia}$ ) e do ganho de peso vivo (GPV, kg/dia), para estimar as exigências líquidas de proteína para qualquer faixa de peso e de ganho de peso. A equação obtida foi a seguinte: $P R(g /$ dia $)=-34,6109+257,956 * G P V J-17,01 * E R$ $\left(r^{2}=0,69\right)$.

A partir dessa equação e tomando-se como referência um animal com peso de corpo vazio de 400 kg e ganho médio diário de 1,0 kg/dia, obtém-se valor de PR ou de exigências líquidas de proteínag/kg para ganho de peso de 132,29 g/kg PCVZ. Por outro lado, a equação adotada pelo NRC (2000) estima o valor de PR em 110,63 g/kg PCVZ, ou seja, 19,57\% inferior ao encontrado neste estudo.

Ao agruparem informações de exigências de proteína de zebuínos no Brasil, Silva et al. (2002b) e Valadares Filho et al. (2006b) obtiveram, respectivamente, as seguintes equações para determinação da proteína retida (PR) para machos nãocastrados: PR (g/dia) = -17,6968 + 192,31*GPVJ - 3,84*ER $\left(\mathrm{r}^{2}=0,44\right)$ e PR $(\mathrm{g} / \mathrm{dia})=26,46-183,49 * \mathrm{GPVJ}+9,38 * \mathrm{ER}$ $\left(r^{2}=0,60\right)$. A partir destas equações, considerando novamente um animal de $400 \mathrm{~kg}$ e ganhando 1,0 kg/dia, obtêm-se valores para PR de 153,80 g/kg PCVZ e 159,74 g/kg PCVZ, respectivamente.

Assim, com base nos valores de proteína retida observados por Silva et al. (2002b), Valadares Filho et al. (2006b) e deste estudo, pode-se inferir que zebuínos, independentemente de serem criados a pasto ou em confinamento, apresentam exigências líquidas de proteína para ganho superiores às preconizadas pelo NRC (2000).

Véras et al. (2007) trabalharam com bovinos Nelore e encontraram o valor de 4,03 g/kg de $\mathrm{PV}^{0,75}$ para exigência de proteína metabolizável para mantença, bem próximo ao de $3,8 \mathrm{~g} / \mathrm{kg} \mathrm{PV}^{0,75}$ adotado pelo NRC (2000) e ao de $4,13 \mathrm{~g} / \mathrm{kg} \mathrm{PV}^{0,75}$ estimado por Valadares et al. (1997). Desta forma, adotou-se neste estudo o valor de 4,00 g/kg PV0,75 para se obterem as exigências de proteína metabolizável para mantença de bovinos Nelore, conforme recomendado por Valadares Filho et al. (2006b).

Nesta pesquisa, as exigências de proteína metabolizável para mantença (PMm) aumentaram com o peso vivo dos animais (Tabela 6), pois foram expressas em relação ao peso (NRC, 2000). Assim, as exigências totais de proteína metabolizável (PMm + PMg) para um animal de 400 kg e ganho diário de 1,0 kg foram de 646,10 g/dia. Valor inferior ao deste estudo foi observado por Véras et al. (2001), que estimaram as exigências de PMt em 624,96 g/dia em animais Nelore não-castrados em confinamento

Entretanto, Silva et al. (2002a) encontraram valor 7,2\% superior (692,96 g/dia). Ao reunirem informações de diferentes 
Tabela 6 - Exigências de proteína metabolizável para mantença (PMm) e para ganho (PMg) de 1,0 kg de peso vivo (g/kg GPV) de bovinos anelorados sob pastejo, em função do peso vivo

\begin{tabular}{ccc}
\hline Peso vivo $(\mathrm{kg})$ & $\mathrm{PMm}^{1}$ & $\mathrm{PMg}^{2}$ \\
\hline 250 & 251,49 & 264,58 \\
300 & 288,34 & 280,94 \\
350 & 323,68 & 294,80 \\
400 & 357,77 & 288,33 \\
\hline
\end{tabular}

$\mathrm{PCVZ}=\mathrm{PV} * 0,8877^{1} 4,00 \mathrm{~g} / \mathrm{kg} \mathrm{PV}^{0,75} ;{ }^{2}$ Exigência líquida/0,492 para PCVZ > $300 \mathrm{~kg}$ e Exigência líquida/[83,4 - (0,114 x PCVZ)] para PCVZ = $300 \mathrm{~kg}$.

autores, Silva et al. (2002b) e Valadares Filho et al. (2006b) encontraram para animais em mesmas condições (400 kg e ganho de 1,0 kg/dia) exigências de PMt de 633,37 g/dia e 707,52 g/dia, respectivamente.

$\mathrm{Na}$ determinação dos consumos de nutrientes digestíveis totais (NDT) e dos requisitos de proteína degradável (PDR) e não-degradável (PNDR) no rúmen em relação ao PV ou ao PCVZ (Tabela 7), foi adotado o protocolo descrito pelo NRC (2000) e o consumo médio de NDT observado nos animais sem suplementação (12,34 g de NDT consumido/kg de PCVZ), com suplementação(15,56g de NDT consumido/kg de PCVZ) e de todos os animais em conjunto (15,38 g de NDT consumido/kg de PCVZ) para conversão das exigências de proteína metabolizável para exigências de proteína degradável no rúmen, proteína não-degradável no rúmen e proteína bruta.

Os animais sob suplementação apresentaram maiores exigências de proteína degradável no rúmen, em virtude do maior consumo de energia em comparação àqueles sem suplementação. Por outro lado, as exigências de PNDR foram maiores nos animais sem suplementação. Segundo Bach et al. (2005), as exigências de PDR no rúmen refletem a síntese de proteína microbiana produzida no rúmen, a qual depende da disponibilidade ruminal de energia e nitrogênio. As maiores exigências de proteína bruta foram observadas para os animais sob suplementação em relação àqueles que não receberam suplemento para qualquer faixa de peso.

De forma geral, à medida que o animal cresce, as exigências de PNDR reduzem, o que, segundo Silva et al. (2002a), possibilita maior participação da proteína degradável no rúmen para o suprimento das exigências totais de proteína bruta e demonstra que, para animais em fase de terminação, maiores níveis de nitrogênio não-proteico podem ser utilizados na dieta. De fato, ao agruparem informações obtidas com animais zebuínos confinados, Silva et al. (2002b) verificaram que animais com peso vivo de $450 \mathrm{~kg}$ não mais apresentaram exigências de PNDR quando toda a PB foi suprida somente pela PDR.

Tomando-se como exemplo um animal em fase de terminação, ou seja, com 400 kg de PV e consumo de MS de $6,83 \mathrm{~kg} /$ dia e 7,92 kg/dia para os animais sem suplementação e aqueles recebendo suplemento, respectivamente, estimaram-se as exigências dietéticas de animais em pastejo para ganharem 1,0 kg de PV em 11,7 e 10,6\% de PB na MS da dieta.

Segundo Bailey \& Duff (2005), os requerimentos de proteína bruta de bovinos de corte em fase de terminação são de 12,0 a 13,0\%. No entanto, os próprios autores descreveram que níveis de PB inferiores não têm prejudicado o desempenho dos animais. De fato, Cavalcante et al. (2005) indicaram que as dietas de bovinos de corte em confinamento na fase terminação, com $400 \mathrm{~kg}$ de peso vivo, podem conter $10,5 \%$ de $\mathrm{PB}$, com desempenho satisfatório. Moraes et al. (2002), em pesquisa com animais

Tabela 7 - Consumo médio de NDT (kg/dia) e exigências de PDR (g/dia), PNDR (g/dia) e PB (g/dia) para mantença e ganho de 1 kg de PV de bovinos anelorados sob pastejo para mantença e ganho de $1 \mathrm{~kg}$ de PV

\begin{tabular}{|c|c|c|c|c|c|}
\hline Item & PV (kg) & $\mathrm{NDT}^{1}$ & $\mathrm{PDR}^{2}$ & $\mathrm{PNDR}^{3}$ & $\mathrm{~PB}$ \\
\hline Sem suplementação & 250 & 2,74 & 355,97 & 344,02 & 699,99 \\
\hline Sob suplementação & & 3,67 & 477,63 & 246,69 & 724,32 \\
\hline Conjunta ${ }^{4}$ & & 3,41 & 443,84 & 273,73 & 717,57 \\
\hline Sem suplementação & 300 & 3,29 & 427,17 & 325,94 & 753,11 \\
\hline Sob suplementação & & 4,41 & 573,16 & 209,15 & 782,31 \\
\hline Conjunta ${ }^{4}$ & & 4,10 & 532,61 & 241,59 & 774,20 \\
\hline Sem suplementação & 350 & 3,83 & 498,36 & 302,36 & 800,73 \\
\hline Sob suplementação & & 5,14 & 668,69 & 116,11 & 834,79 \\
\hline Conjunta ${ }^{4}$ & & 4,78 & 621,38 & 203,96 & 825,33 \\
\hline Sem suplementação & 400 & 4,38 & 569,56 & 229,61 & 799,17 \\
\hline Sob suplementação & & 5,88 & 764,22 & 73,89 & 838,10 \\
\hline Conjunta $^{4}$ & & 5,46 & 710,14 & 117,15 & 827,29 \\
\hline
\end{tabular}

PCVZ $=$ PV $* 0,88,77 ;{ }^{1}$ Consumo; ${ }^{2} \mathrm{PDR}=130 \mathrm{~g} / \mathrm{kg}$ NDT $\times 1,11 ;{ }^{3} \mathrm{PNDR}=\left[\mathrm{PM}_{\text {Total }}-(\mathrm{PDR} \times 0,64)\right] / 0,8 ;{ }^{4}$ Consumo de NDT de todos animais. 
em terminação a pasto, encontraram ganho médio diário próximo de 1,0 kg fornecendo uma dieta com 10,7\% de PB. Desta forma, os valores encontrados estão dentro da faixa considerada adequada para bovinos de corte em terminação.

O conhecimento das exigências de PDR e de NDT em bovinos de corte a pasto possibilita a formulação de suplementos que permitam balanço adequado entre esses nutrientes. Assim, os efeitos associativos negativos podem ser reduzidos com o fornecimento de grandes quantidades de suplementos ricos em carboidratos não-fibrosos em dietas à base de forragem. Além disso, do ponto de vista econômico, a associação de grãos e ureia é uma alternativa para redução dos custos de produção.

\section{Conclusões}

As exigências líquidas de proteína para ganho de peso de animais anelorados não-castrados em pastejo, em g/dia, podem ser obtidas a partir da equação: PR (g/dia) = $-34,6109+257,956 *$ GPVJ-17,01*ER.

\section{Referências}

AGRICULTURAL RESEARCH COUNCIL - ARC. The nutrient requirements of ruminants livestock. London: 1980. 351p.

BACH, A.; CALSAMIGLIA, S.; STERN, M.D. Nitrogen metabolism in the rumen. Journal of Dairy Science, v.88 (suppl. E), p.9-21, 2005.

BACKES, A.A.; PAULINO, M.F.; ALVES, D.D. et al. Composição corporal e exigências energéticas e protéicas de bovinos mestiços leiteiros e zebu, castrados, em regime de recria e engorda. Revista Brasileira de Zootecnia, v.34, n.1, p.257-267, 2005.

BALDWIN, R.L. Energy requirements for maintenance and production. In: BALDWIN, R.L. (Ed.) Modeling ruminant digestion and metabolism. London: Chapman \& Hall, 1995. p.148-188.

BAILEY, C.R.; DUFF, G.C. Protein requirements of finishing beef cattle. In: SOUTHWEST NUTRITION CONFERENCE, 2005, Tempe. Proceedings... Tempe: University of Arizona, 2005. p.78-85.

BERG, R.T.; BUTTERFIELD, R.M. New concepts of cattle growth. 1.ed. Sydney: Sydney University Press, 1976. 240p.

BOIN, C. Alguns dados sobre exigências de energia e proteína de zebuínos. In: SIMPÓSIO INTERNACIONAL SOBRE EXIGÊNCIAS NUTRICIONAIS DE RUMINANTES, 1995, Viçosa, MG. Anais... Viçosa, MG: Universidade Federal de Viçosa, 1995. p.457-465.

CAVALCANTE, M.A.B.; PEREIRA, O.G.; VALADARES FILHO, S.C. et al. Níveis de proteína bruta em dietas para bovinos de corte: consumo, digestibilidade total e desempenho produtivo. Revista Brasileira de Zootecnia, v.34, n.3, p.711-719, 2005.

FONTES, C.A.A.; OLIVEIRA, R.C.; ERBESDOBLER, E.D. et al. Conteúdo de energia líquida para mantença e ganho do capimelefante e mudanças na composição corporal de novilhos em pastejo, durante a estação chuvosa. Revista Brasileira de Zootecnia, v.34, n.5, p.1711-1720, 2005.
FREGADOLLI, F.L. Composição corporal e exigências nutricionais de novilhos de três grupos genéticos em pastejo. 2005, 85f. Tese (Doutorado em Zootecnia) Universidade Estadual Paulista, Faculdade de Ciências Agrárias e Veterinárias, Jaboticabal.

FREITAS, J.A.; QUEIROZ, A.C.; DUTRA, A.R. et al. Composição do ganho e exigências de energia e proteína para ganho de peso em bovinos Nelore puros e mestiços, em confinamento. Revista Brasileira de Zootecnia, v.35, n.3, p.886-893, 2006.

MORAES, E.H.B.K.; PAULINO, M.F.; ZERVOUDAKIS, J.T. et al. Níveis de uréia em suplementos múltiplos para terminação de bovinos mestiços em pastejo no período da seca: ganho de peso e rendimento de carcaça. In: REUNIÃO ANUAL DA SOCIEDADE BRASILEIRA DE ZOOTECNIA, 2002, Recife. Anais... Recife: Sociedade Brasileira de Zootecnia, 2002. (CD-ROM).

NATIONAL RESEARCH COUNCIL - NRC. Nutrient requirements of beef cattle. 7.rev.ed. Washington, DC.: National Academy Press, 2000. 242p.

NOLLER, C.H.; NASCIMENTO JR., D.; QUEIROZ, D.S. Exigências nutricionais de animais em pastejo. In: SIMPÓSIO SOBRE MANEJO DE PASTAGEM, 13., 1996, Piracicaba. Anais... Piracicaba: Fundação de Estudos Agrários "Luiz de Queiroz", p.151-184. 1996.

PAULINO, P.V.R.; COSTA, M.A.; VALADARES FILHO, S.C. et al. Exigências nutricionais de zebuínos: Proteína. Revista Brasileira de Zootecnia, v.33, n.3, p.759-769, 2004.

PAULINO, P.V.R.; VALADARES FILHO, S.C.; COSTA, M.A.L. et al. Validation of the $9-11^{\text {th }}$ rib cut to estimate the chemical composition of the dressed carcass and of the whole empty body of zebu cattle. Livestock Production Science, v.93, n.1, p.245-253, 2005.

REGAZZI, J.A. Teste para verificar a identidade de modelos de regressão. Pesquisa Agropecuária Brasileira, v.31, n.1, p.1-17, 1996.

SILVA, D.J.; QUEIROZ, A.C. Análise de alimentos: métodos químicos e biológicos. 3.ed. Viçosa, MG: UFV, Imprensa Universitária, 2002. 165p.

SILVA, F.F.; VALADARES FILHO, S.C.; ÍTAVO, L.C.V. et al. Composição corporal e requisitos energéticos e protéicos de bovinos nelore, não-castrados, alimentados com rações contendo diferentes níveis de concentrado e proteína. Revista Brasileira de Zootecnia, v.31, n.1, p.503-513, 2002a.

SILVA, F.F.; VALADARES FILHO, S.C.; ÍTAVO, L.C.V. et al. Exigências líquidas e dietéticas de energia, proteína e macroelementos minerais de bovinos de corte no Brasil. Revista Brasileira de Zootecnia, v.31, n.2, p.776-792, 2002b.

VALADARES, R.F.D.; GONÇALVES, L.C.; RODRIGUEZ, N.M. et al. Níveis de proteína em dietas de bovinos. 2. Consumo, digestibilidades e balanço de compostos nitrogenados. Revista Brasileira de Zootecnia, v.26, n.6, p.1259-1263, 1997.

VALADARES FILHO, S.C.; PAULINO, P.V.R.; VALADARES, R.F.D. et al. Exigências nutricionais de zebuínos no Brasil: II. Proteína. In: VALADARES FILHO, S.C.; PAULINO, P.V.R; MAGALHÃES, K.A. (Eds.) Exigências nutricionais de zebuínos e tabelas de composição de alimentos BR-Corte. 1.ed. Viçosa, MG: UFV, DZO, 2006b. 142p.

VÉRAS, R.M.L.; VALADARES FILHO, S.C.; VALADARES R.D. Balanço de compostos nitrogenados e estimativa das exigências de proteína de mantença de bovinos Nelore de três condições sexuais. Revista Brasileira de Zootecnia, v.36, n.4, p.1212-1217, 2007.

VÉRAS, A.S.C.; VALADARES FILHO, S.C.; SILVA, J.F.C. et al. predição da composição corporal e dos requisitos de energia e proteína para ganho de peso de bovinos, não-castrados, alimentados com rações contendo diferentes níveis de concentrado. Revista Brasileira de Zootecnia, v.30, n.3, p.1127-1134, 2001 (supl. 1). 